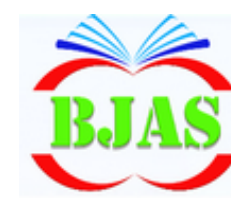

ISSN $1814-5868$
Available online at http://bajas.edu.iq

https://doi.org/10.37077/25200860.2021.34.sp1.8

College of Agriculture, University of Basrah

Basrah J. Agric. Sci., 34(Special Issue 1), 73-80, 2021
Basrah Journal

of Agricultural

Sciences

E-ISSN: 2520-0860

\title{
Detecting BSR-infected Oil Palm Seedlings using Thermal Imaging
}

\section{Technique}

Siti N. Á. M. Johari' ${ }^{1}$, Siti Khairunniza-Bejo ${ }^{1 *}$, Ghaibulna Abdol Lajis ${ }^{1}$, Leona D. J.

DaimDai $^{2}$, Neoh B. Keat ${ }^{2}$, Yap Yun $\mathrm{Ci}^{2}$, \& Nalisha Ithnin ${ }^{2}$

${ }^{1}$ Department of Biological and Agricultural Engineering, Faculty of Engineering, Universiti

Putra Malaysia, Selangor, Malaysia

${ }^{2}$ Integrative and Applied Biology Department, Sime Darby Technology Centre Sdn Bhd, UPM-MTDC Technology Centre III, Universiti Putra Malaysia, Selangor, Malaysia

*Corresponding author E-mail: skbejo@upm.edu.my

Received 19 September 2019; Accepted 10 May 2021; Available online 20 August 2021

\begin{abstract}
Basal Stem Rot (BSR) is the most destructive disease instigated by a white wood rotting fungus called Ganoderma boninense, which cause great economic setback in oil palm productivity. It attacks the basal stem of oil palm trees, causing them to slowly rot. It also affects the xylem tissues that eventually interrupt water transportation to the upper part of the oil palm, turning the leaves at the frond become yellow. This problem should be prevented during nursery stage by separating between healthy and BSR-infected seedling. Therefore, this study focuses on the potential use of thermal imaging for detecting BSR in oil palm at seedling. Thermal images of oil palm seedling from healthy and BSR-infected were captured and processed to extract several thermal properties of the seedling, i.e., maximum, minimum, mean, and standard deviation of pixel intensity value. These values were then undergone statistical analysis to identify its significant different in differentiating healthy and BSR-infected seedling. Several classification models were tested including Linear Discriminant Analysis (LDA), Quadratic Discriminant Analysis (QDA), Support Vector Machine (SVM) and k-Nearest Neighbour (kNN). Principal Component Analysis (PCA) was used to reduce the dimensionality of the dataset. The results demonstrated that the highest accuracy achieved at $80.0 \%$ using SVM (fine gaussian) classification model with PC1 and PC3 as the input parameter. This summarizes the potential of thermal imaging in detecting BSR-infected oil palm trees at seedling stage.
\end{abstract}

Keywords: BSR, Oil palm, Thermal imaging, Image processing, Machine learning.

\section{Introduction}

Malaysia is known as world's second largest producer and exporter of palm oil production. However, according to Malaysian Palm Oil Board (MPOB), the Malaysia's palm oil stocks fell $0.79 \%$ in July 2019. It decreases to 2.39 million tonnes from 2.41 million tonnes. One of the problems faced by oil palm plantation is Basal Stem Rot (BSR) disease (Roslan \& Idris,
2012). BSR disease, caused by Ganoderma boninense is the most serious disease for oil palm trees in Malaysia. The fungus attacks the oil palm trees initially causing loss of production yield and finally eradicate the trees (Flood et al., 2000). It can be identified when the young leaves failed to open. This indicates the stem is damage and restrict the water uptake (Corley \& Tinker, 2004). When the 
disease is at critical stage, more fronds shrivels and dangles like skirt structure around the trunk (Turner \& Gillbank, 1974). Other noticeable symptoms are flattening of the crown (Rees et al., 2012).

BSR detection is very difficult due to very mild symptom at early stage of infection. Common method of identifying BSR infection is by visually inspect the foliar symptom and fungus fruiting bodies (Basidiomycota mushroom). This job requires an expert worker. Thus, non-destructive methods with precise preparation are needed for an early detection of the BSR infection. There were many methods and approaches in detecting, classifying and differentiating healthy and BSR-infected trees using remote sensing technique such as hyperspectral remote sensing (Mohamad Anuar et al., 2015), multispectral remote sensing (KhairunnizaBejo et al., 2015; Santoso et al., 2011), terrestrial laser scanning (Khairunniza-Bejo \& Vong, 2014; Azuan et al., 2019), electronic nose system (Markom et al., 2009), tomographic remote sensing (Abu Seman et al., 2010; Hamidon \& Mukhlisin, 2014), midinfrared spectroscopy (Liaghat et al., 2014) and field spectroscopy (Mohamad Anuar et al., 2012). Nonetheless, these existing techniques were not completely efficient. Various aspect in term of cost of the equipment, time to complete the process of detection and accuracy of the results still need to be improved. Therefore, some improvement of existing methods and new approach are required to further upgrade the detection method.

Thermal imaging is a technique which convert an invisible radiation pattern into visible images for feature extraction and analysis. It can be applied in all fields where temperature difference can be utilized to assist any evaluation and diagnosis. Thermal imaging has been used widely in agricultural applications especially in nursery monitoring (Kraner et al., 2010), irrigation scheduling (Panigadaa et al., 2014), soil salinity detection (Urrestarazu, 2013), yield estimation ( $\mathrm{Hu}$ et al., 2013), maturity evaluation (Gonçalves et al., 2016) and bruise detection (Kim et al., 2014). Thermal imaging also has been used in detecting disease in plant. Oerke et al. (2006) used thermal infrared to detect Pseudoperonospora cubensis that causes downy mildew in cucumber. In this study, it has been found that the maximum temperature difference (MTD) within leaf or a canopy was suitable to differentiate between infected and healthy tissue under controlled and noncontrolled environment. Jafari et al. (2017) stated that thermal imaging was able to detect powdery mildew (Podosphaera pannosa var. rosae) and grey mould (Botrytis cinerea) disease in rose plant. According to Sankaran et al. (2013), citrus greening disease can be detected using thermal imaging method by measuring the canopy temperature which indicate stress due the infection of the disease. Therefore, the main objective of this study is to detect the BSR-infected oil palm seedling at nursery stage using thermal imaging and various classification models.

\section{Materials \& Methods}

\section{Image acquisition}

Image acquisition was done at nursery Sime Darby Banting, Selangor, Malaysia. A total of 100 oil palm seedlings were selected and used for this study. The age of the seedling was 16 months old with two meters height. The samples were categorized into two groups; healthy and BSR-infected seedlings, (artificially infected using rubberwood block and sitting techniques (Naidu et al., 2018)). The healthiness status of the seedling was 
manually identified based on visual symptoms and confirmed by the expert from Sime Darby. There were 50 samples per each group. A handheld thermal camera, FLIR E60 (FLIR Systems, Inc., Wilsonville, United States) with ability to measure a temperature range between $20^{\circ} \mathrm{C}$ to $+650^{\circ} \mathrm{C}$ was chosen to acquire thermal image of the sample (Fig. 1). The images were captured randomly from three different angles. The illustration of the random angle captured is shown in fig. (2). In this study, the images captured were only focused on the canopy section. The distance between the seedling and camera was one meter away, as the images covered the entire canopy of the seedling (Fig. 2). The images were taken from $12 \mathrm{pm}$ to $2 \mathrm{pm}$ noon. Both setups were following work done by Abdul Razak (2015).

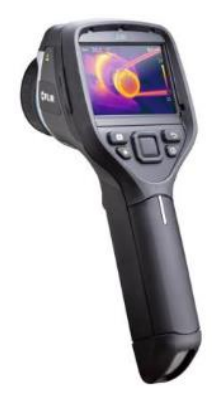

Fig. (1): FLIR E60 (FLIR Systems, Inc., Oregon, United States) thermal camera.

In this study, the parameters of the thermal camera were set into fixed value to keep the consistency during the image acquisition (Abdul Razak, 2015). The parameters involved were emissivity (0.98), reflected apparent temperature $\left(20.0^{\circ} \mathrm{C}\right)$, atmospheric temperature $\left(20.0^{\circ} \mathrm{C}\right)$ and relative humidity $(50.0 \%)$.

\section{Image processing}

Thermal images were pre-processed using FLIR Quickreport 1.2 (FLIR Systems, Inc., Wilsonville, United States). The temperature scale of the image was standardized into scale from $24-34^{\circ} \mathrm{C}$. The purpose was to ensure the pixel intensity is referring to the same temperature representation. After that, all the thermal images were pre-processed using MATLAB software (Version R2019b, The Mathworks Inc., Massachusetts, United States) before being analysed to extract important properties. The process was started with image cropping to remove the temperature scale on the left side of the images (Fig. 3).

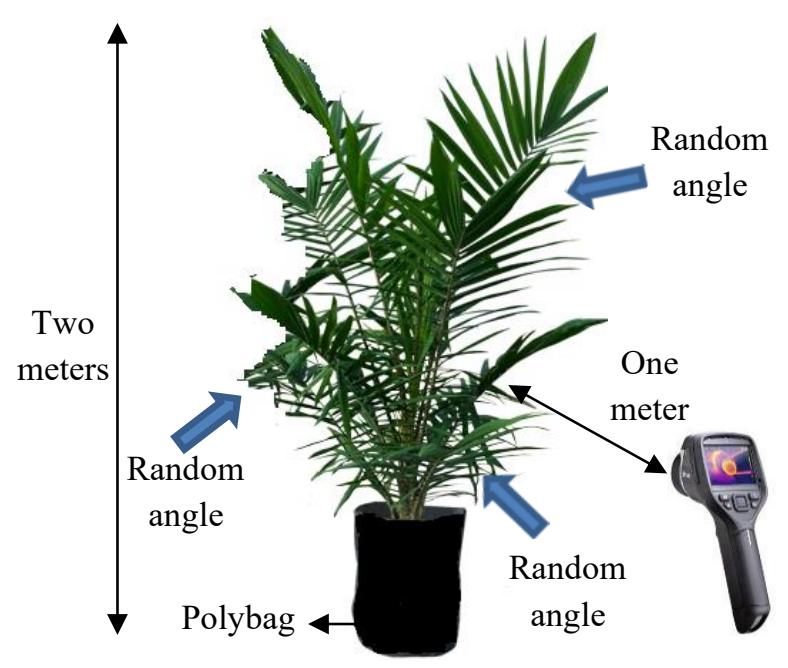

Fig. (2): Illustration of images captured from random angle

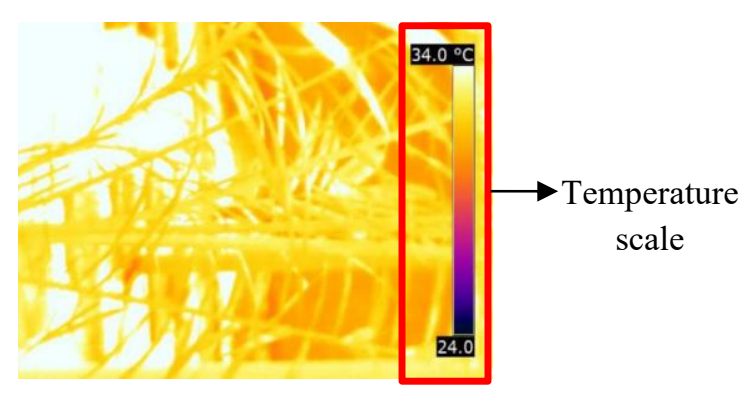

Fig. (3): Thermal image of oil palm seedling (canopy section)

The image segmentation technique was then applied to separate the pixels of the palm trees (seedling) and its background by using Otsu's thresholding method (Otsu, 1979). The segmented image was used as a mask layer to create a region of interest (ROI) of the image. The purpose of the ROI was to select the seedling canopy only. Therefore, only white 
pixel in the ROI was analysed for feature extraction (Fig. 4).

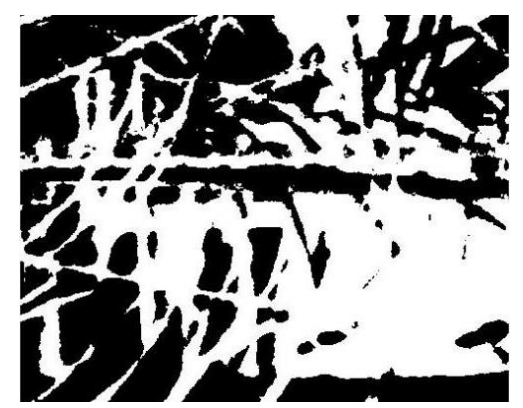

Fig. (4): Binary mask layer image created after thresholding.

\section{Image analysis}

Information extracted from the ROI image denoted by $A=\left\{a_{i}\right\}_{i=1}^{N}$ are defined as follows:

- Maximum pixel intensity value, $\mathrm{I}_{\mathrm{MAX}}=$ $\max (\mathrm{A})$

- Minimum pixel intensity value, $\mathrm{I}_{\mathrm{MIN}}=\min$ (A)

- Mean pixel intensity value, $\mathrm{I}_{\mathrm{MEAN}}=\frac{\sum_{i=1}^{N} a_{i}}{N}$

- Standard deviation of pixel intensity value,

$$
\mathrm{ISD}_{\mathrm{SD}}=\sqrt{\frac{1}{N} \sum_{i=1}^{N}\left(a_{i}-I_{M E A N}\right)^{2}}
$$

where $N$ is total number of pixel and $a_{i}$ is pixel value at $i$.

Therefore, since there were three images for each sample, thus an average value was used to represent each sample to interpret the characteristics of healthy and BSR-infected oil palm seedling. Statistical analysis of t-test was done to identify the significant of each information in differentiating between healthy and infected seedling.

After identifying the significant information extracted using t-test, image classification models were used to organize them into precise categories. Several classification models were used in this study, namely, Linear
Discriminant Analysis (LDA), Quadratic Discriminant Analysis (QDA), Support Vector Machine (SVM) and k-Nearest Neighbour $(\mathrm{kNN})$. The classification was done using Classification Learner App from Statistics and Machine Learning Toolbox of MATLAB software (Version R2019b, The Mathworks Inc., Massachusetts, United States). For SVM and $\mathrm{kNN}$, different type of kernels was evaluated to obtain the best classification model. Hence, 14 classification models were used in the classification phase as shown in table (1).

Table (1): List of classification models

\begin{tabular}{|c|c|c|}
\hline No. & Type of classification & Type of kernel \\
\hline 1 & $\begin{array}{l}\text { Linear Discriminant } \\
\text { (LDA) }\end{array}$ & - \\
\hline 2 & $\begin{array}{l}\text { Quadratic Discriminant } \\
\text { (QDA) }\end{array}$ & - \\
\hline 3 & \multirow{6}{*}{$\begin{array}{l}\text { Support Vector } \\
\text { Machine (SVM) }\end{array}$} & Linear \\
\hline 4 & & Quadratic \\
\hline 5 & & Cubic \\
\hline 6 & & Fine Gaussian \\
\hline 7 & & $\begin{array}{l}\text { Medium } \\
\text { Gaussian }\end{array}$ \\
\hline 8 & & $\begin{array}{l}\text { Coarse } \\
\text { Gaussian }\end{array}$ \\
\hline 9 & \multirow{6}{*}{$\begin{array}{l}\text { k-Nearest } \\
(\mathrm{kNN})\end{array}$} & Fine \\
\hline 10 & & Medium \\
\hline 11 & & Coarse \\
\hline 12 & & Cosine \\
\hline 13 & & Cubic \\
\hline 14 & & Weighted \\
\hline
\end{tabular}

Besides, a Principal Component Analysis (PCA) was also used to reduce the redundancy of dataset while preserving the significant features for classification. It was done using multivariate data analysis statistical software, The Unscrambler X 10.4 (CAMO Software AS, Oslo, Norway). The input was divided into two datasets; training dataset which is 70 
$\%$ of total 100 number of samples and testing dataset which consists of the remaining $30 \%$. The information extracted from PCA was then used as the input parameters for classification model listed in table (1).

\section{Results \& Discussion:}

\section{T-test analysis}

Table (2) shows results of the t-test.

Table (2): T-test result for each information extracted.

\begin{tabular}{lcc}
\hline Feature & $\boldsymbol{P}$ value & Significance \\
\hline IMIN & 0.0000 & YES \\
\hline IMAX $_{\text {MAN }}$ & 0.0004 & YES \\
\hline IMEAN & 0.0443 & YES \\
\hline ISD & 0.1608 & NO \\
\hline
\end{tabular}

As shown in table (2), $\mathrm{I}_{\text {MIN }}$, IMAX and IMEAN have $p$-value less than $(p=0.05)$. Thus, from the t-test result, it can be summarised that all the information extracted from the thermal images can be used to differentiate between healthy and BSR-infected seedling except for the $\mathrm{I}_{\mathrm{SD}}$. Therefore, classification was done using only three significant information: IMIN, $\mathrm{I}_{\text {MAX }}$ and IMEAN. Results of classification is shown in table (3).

Table (3): Classification accuracy using only significant information as input parameters

\begin{tabular}{lc}
\hline \multicolumn{1}{c}{$\begin{array}{c}\text { Type of } \\
\text { classification }\end{array}$} & $\begin{array}{c}\text { Classification } \\
\text { accuracy (\%) }\end{array}$ \\
\hline $\begin{array}{l}\text { Linear } \\
\text { Discriminant }\end{array}$ & 69.0 \\
\hline $\begin{array}{l}\text { Quadratic } \\
\text { Discriminant }\end{array}$ & 61.0 \\
\hline SVM (Linear) & 67.0 \\
\hline SVM (Quadratic) & 68.0 \\
\hline SVM (Cubic) & 64.0 \\
\hline SVM (Fine & 65.0 \\
Gaussian) & 69.0 \\
\hline $\begin{array}{l}\text { SVM (Medium } \\
\text { Gaussian) }\end{array}$ & 68.0 \\
\hline SVM (Coarse & \\
\hline
\end{tabular}

\begin{tabular}{ll}
\hline Gaussian) & \\
\hline KNN (Fine) & 61.0 \\
\hline KNN (Medium) & 68.0 \\
\hline KNN (Coarse) & 50.0 \\
\hline KNN (Cosine) & $\mathbf{7 0 . 0}$ \\
\hline KNN (Cubic) & 66.0 \\
\hline KNN (Weighted) & 63.0 \\
\hline
\end{tabular}

Based on table (3), kNN (cosine) shows the highest accuracy (70 \%), followed by SVM (medium gaussian) and LDA, which was 69.0 $\%$. The lowest accuracy was $50.0 \%$ from $\mathrm{kNN}$ (coarse). It can be summarised that this significant information was insufficient to produce high accuracy using the classification model. Thus, instead of using only significant information, the models were tested using all extracted information to improvise the classification. Results are shown in table (4).

Table (4): Classification accuracy using all information as input parameter.

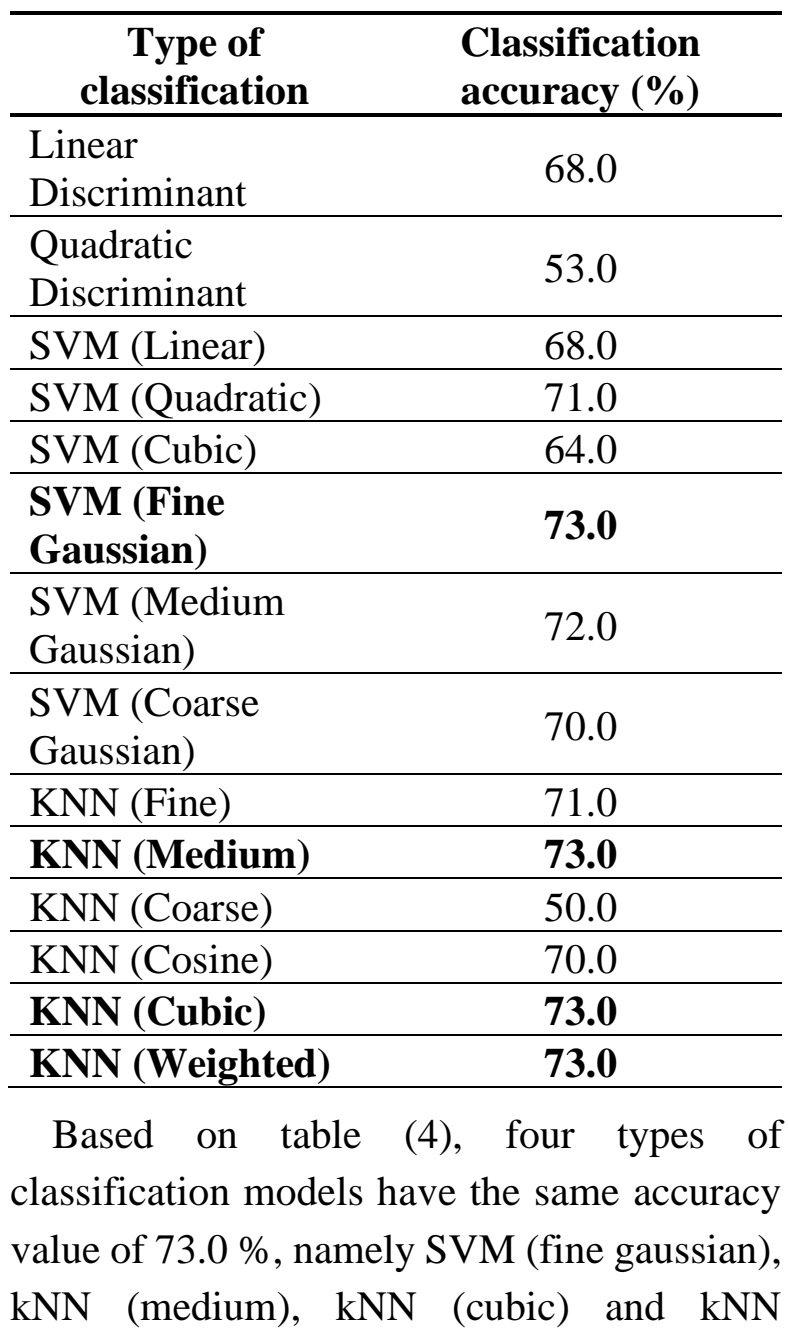


(weighted). The lowest accuracy was $50.0 \%$ from $\mathrm{kNN}$ (coarse), same as when using only significant information as the input parameters. Hence, it can be summarized that the classification done by using all information extracted from the thermal images were able to produce higher accuracy to differentiate healthy and BSR-infected oil palm seedling. Although the value of ISD is not significant, however it can slightly improve the percentage of accuracy.

\section{Principle Component Analysis (PCA)}

Results of the classification using Principle Component (PC) data is shown in table (5). All information was used as an input parameter of the PCA, resulting four PCs namely PC1, PC2, PC3 and PC4. Different combination of PCs was used as the input parameters, i.e., PC1 \& PC2, PC1 \& PC3, PC1 \& PC4, PC2 \& PC3, PC3 \& PC4, and PC3 \& PC4. Results tabulated in table (5) has shown that the highest accuracy was gathered from a classification model that has been developed using PC1 and PC3.

From the classification accuracy tabulated in table (5), SVM (fine gaussian) gave highest accuracy of $80.0 \%$, followed by SVM (coarse gaussian) which was $74.3 \%$, compared to other classification. However, the lowest accuracy of classification was $50.0 \%$ also from kNN (coarse).

Table (5): Classification accuracy using PC1 and PC3 as input parameters.

\begin{tabular}{lc}
\hline \multicolumn{1}{c}{$\begin{array}{c}\text { Type of } \\
\text { classification }\end{array}$} & $\begin{array}{c}\text { Classification } \\
\text { accuracy }(\%)\end{array}$ \\
\hline $\begin{array}{l}\text { Linear } \\
\text { Discriminant }\end{array}$ & 72.9 \\
\hline $\begin{array}{l}\text { Quadratic } \\
\text { Discriminant }\end{array}$ & 64.3 \\
\hline SVM (Linear) & 70.0 \\
\hline SVM (Quadratic) & 68.6 \\
\hline SVM (Cubic) & 62.9 \\
\hline SVM (Fine & $\mathbf{8 0 . 0}$ \\
\hline
\end{tabular}

\begin{tabular}{ll}
\hline Gaussian) & \\
\hline $\begin{array}{l}\text { SVM (Medium } \\
\text { Gaussian) }\end{array}$ & 72.9 \\
\hline $\begin{array}{l}\text { SVM (Coarse } \\
\text { Gaussian) }\end{array}$ & 74.3 \\
\hline KNN (Fine) & 58.6 \\
\hline KNN (Medium) & 65.7 \\
\hline KNN (Coarse) & 50.0 \\
\hline KNN (Cosine) & 72.9 \\
\hline KNN (Cubic) & 68.6 \\
\hline KNN (Weighted) & 65.7 \\
\hline
\end{tabular}

It indicates that $\mathrm{kNN}$ (coarse) classifier did not give any accuracy difference when using different types of the input parameters. Therefore, it can be concluded that the classification performed well by using features extracted from PCA.

\section{Conclusions:}

This paper has successfully analysed the potential use of thermal image to detect healthy and BSR-infected oil palm seedling at nursery stage. In this study, it has been shown that more input parameters can help to increase percentage accuracy of the classification model. KNN classifier with kernel cosine, medium, cubic, and weighted performed well when using the raw information as the inputs. Conversely, the performance of these classification models seems decreasing when using the transformed data, PCs. SVM (fine gaussian) shows more consistent results. It gave the highest accuracy most of the time and identified as the best classification model among other approaches with $80 \%$ accuracy when using PC1 and PC3 as the input parameters. For future work, this method can be expanded by considering different section of seedling (other than canopy) and extending the scope of detection to its severity level of infection. 


\section{Acknowledgement:}

The authors would like to acknowledge the Ministry of Higher Education (MOHE) and Universiti Putra Malaysia (UPM) for sponsoring this research under Nanomite Grant, project number UPM/700-2/1/LRGSNANOMITE/5526305.

\section{References:}

Abdul Razak, N. E. (2015). Detection of basal stem rot in oil palm tree using thermal imaging. Bachelor Thesis, Universiti Putra Malaysia.

Abu Seman, I., Mohd Su'ud, M., Loonis, P., \& Wahid, M. B. (2010). GanoSken for early detection of Ganoderma infection in oil palm. $M P O B$ Information Series, 3-6. http://palmoilis.mpob.gov.my/publications/TOT/T T-442.

Azuan, N. H., Khairunniza-Bejo, S., Abdullah, A. F., Kassim, M. S. M., \& Ahmad, D. (2019). Analysis of changes in oil palm canopy architecture from basal stem rot using terrestrial laser scanner. Plant Disease, 103, 3218-3225. https://doi.org/10.1094/PDIS-10-18-1721-RE

Corley, R.H.V. \& Tinker, P.B. (2004). The oil palm (Elaeisguineensis Jacq). Oxford: Wiley-Blackwell, 4th edition. $592 \mathrm{pp}$.

Flood, J., Hasan, Y., Turner, P. D., \& O’Grady, E. B. (2000). The spread of Ganoderma from infective sources in the field and its implications for management of the disease in oil palm. In J. Flood, J., Bridge, P. D., \& Holderness, M. (Eds.), Ganoderma Diseases of Perennial Crops, 101-112. https://www.cabi.org/cabebooks/ebook/20073012 586

Gonçalves, B. J., Giarola, T. M. de O., Pereira, D. F., Vilas Boas, E. V. de B., \& de Resende, J. V. (2016). Using infrared thermography to evaluate the injuries of cold-stored guava. Journal of Food Science and Technology, 53, 1063-1070. https://doi.org/10.1007/s13197-015-2141-4

Hamidon, N. A., \& Mukhlisin, M. (2014). A review of application of computed on early detection of basal stem rot tomography disease. Jurnal Teknologi (Sciences \& Engineering), 70, 45-47 www.jurnalteknologi.utm.my
Hu, Z.-F., Zhang, L.-D., Wang, Y.-X., Shamaila, Z., Zeng, A.-J., Song, J.-L., Liu, Y.-J., Wolfram, S., Joachim, M., He, X.-K. (2013). Application of BP neural network in predicting winter wheat yield based on thermography technology. Spectroscopy and Spectral Analysis, 33, 1587-1592.

Jafari, M., Minaei, S., \& Safaie, N. (2017). Detection of pre-symptomatic rose powdery mildewand graymold diseases based on thermal vision. Infrared Physics and Technology, 85, 170-183. https://doi.org/10.1016/j.infrared.2017.04.023

Khairunniza-Bejo, S., \& Vong, C. N. (2014). Detection of basal stem rot infected oil palm tree using laser scanning data. Agriculture and Agricultural Science Procedia, 2, 156-164. https://doi.org/10.1016/j.aaspro.2014.11.023

Khairunniza-Bejo, S., Yusoff, Y., Nik Yusoff, N. S., Abu Seman, I., \& Anuar, M. I. (2015). Identification of healthy and BSR-infected oil palm trees using color indices. International Journal of Biological, Biomolecular, Agricultural, Food and Biotechnological Engineering, 9, 876-879.

Kim, G., Kim, G.-H., Park, J., Kim, D.-Y., \& Cho, B.K. (2014). Application of infrared lock-in thermography for the quantitative evaluation of bruises on pears. Infrared Physics \& Technology, 63 ,

133-139. http://dx.doi.org/10.1016/j.infrared.2013.12.015

Kranner, I., Kastbergerb, G., Hartbauerb, M. \& Pritcharda, H. W. (2010). Noninvasive diagnosis of seed viability using infrared thermography. Proceedings of the National Academy of Sciences of the United States of America, 107, 3912-3917. https://doi.org/10.1073/pnas.0914197107

Liaghat, S., Mansor, S., Ehsani, R., Shafri, H. Z. M., Meon, S., \& Sankaran, S. (2014). Mid-infrared spectroscopy for early detection of basal stem rot disease in oil palm. Computers and Electronics in Agriculture, $\quad 101, \quad 48-54$. https://doi.org/10.1016/j.compag.2013.12.012

Markom, M. A., Shakaff, A. Y. M., Adom, A. H., Ahmad, M. N., Hidayat, W.,Abdullah, A. H., \& Fikri, N. A. (2009). Intelligent electronic nose system for basal stem rot disease. Computers and Electronics in Agriculture, 66, 140-146. https://doi.org/10.1016/J.COMPAG.2009.01.006

Mohamad Anuar, I., Abu Seman, I., Nor Maris, N., \& Bahrom, E. (2015). Spectral based analysis of 


\section{Johari et al. Basrah J. Agric. Sci., 34(Special Issue 1): 73-80, 2021}

airborne hyperspectral remote sensing image for detection of Ganoderma disease in oil palm. International Conference on Biological and Environmental Science (BIOES 2015), 13-20. Corpus ID: 29661453.

Mohamad Anuar, I., Abu Seman, I., Wahid, M. B., Mohd Noor, N., \& Mohd Shafri, H. Z. (2012). Field spectroscopy for detection of Ganoderma disease in oil palm. MPOB Information Series, (MPOB TT No 532). www.mpob.gov.my.

Naidu, Y.; Siddiqui, Y.; Rafii, M. Y.; Saud, H. M. \& Idris, A. S. (2018). Inoculation of oil palm seedlings in Malaysia with white rot hymenomycetes: Assessment of pathogenicity and vegetative growth. Crop Protection, 110, 146-154.

DOI: 10.1016/j.cropro.2018.02.018

Oerke, E.-C., Steiner, U., Dehne, H.-W., \& Lindenthal, M. (2006). Thermal imaging of cucumber leaves affected by downy mildew and environmental conditions. Experimental Botany, 57, 2121-2132. https://doi.org/10.1093/jxb/erj170

Otsu, N., (1979). A threshold selection method from gray-level histograms. IEEE Trans. Sys. Man. Cyber. 9 (1), 62-66.

Panigadaa, C., Rossinia, M., Meronia, M., Ciliaa, C., Busettoa, L., Amaduccid, S., et al. (2014). Fluorescence, PRI and Canopy Temperature for Water Stress Detection in Cereal Crops. International Journal of Applied Earth Observation and Geoinformation, 30, 167-178. http://dx.doi.org/10.1016/j.jag.2014.02.002

Rees, R. W., Flood, J., Hasan, Y., Wills, M. A., \& Cooper, R. M. (2012). Ganoderma boninense basidiospores in oil palm plantations: Evaluation of their possible role in stem rots of Elaeis guineensis. Plant Pathology, 61, 567-578. https://doi.org/10.1111/j.1365-3059.2011.02533.

Roslan, A., \& Idris, A.S. (2012). Economic impact of Ganoderma incidence on Malaysian oil palm plantation - A case study in Johor in oil palm. Industry Economic Journal, 12, 24-30.

http://palmoilis.mpob.gov.my/publications/OPIEJ/opie jv12n1-Roslan.pdf

Sankaran, S., Maja, J. M., Buchanon, S., \& Ehsani, R. (2013). Huanglongbing(Citrus Greening) detection using visible near infrared and thermal imaging techniques.Sensors,

https://doi.org/10.3390/s130202117

Santoso, H., Gunawan, T., Jatmiko, R. H., Darmosarkoro, W., \& Minasny, B. (2011). Mapping and identifying basal stem rot disease in oil palms in North Sumatra with QuickBird imagery. Precision Agriculture, 12, 233-248. https://doi.org/10.1007/s11119-010-9172-7

Turner, P. D., \& Gillbank, R. A. (1974). Oil palm cultivation and management. Incorporated Society of Planters. University Press, Kuala Lumpur, Malaysia, $672 \mathrm{pp}$. https://catalogue.nla.gov.au/Record/1478450

Urrestarazu, M. (2013) Infrared Thermography Used to Diagnose the Effects of Salinity in a Soilless Culture. Quantitative InfraRed Thermography Journal, 10 , 1-8. http://dx.doi.org/10.1080/17686733.2013.763471 